\title{
Subclinical left ventricular diastolic dysfunction and incident type 2 diabetes risk: the Korean Genome and Epidemiology Study
}

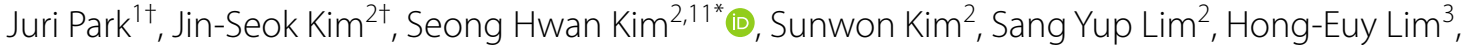 \\ Goo-Yeong Cho ${ }^{4}$, Ki-Chul Sung ${ }^{5}$, Jang-Young Kim ${ }^{6}$, Inkyung Baik ${ }^{7}$ Kwang Kon Koh ${ }^{8}$, Jung Bok Lee ${ }^{9}$, \\ Seung Ku Lee ${ }^{10}$ and Chol Shin ${ }^{10}$
}

\begin{abstract}
Background: Subclinical left ventricular (LV) diastolic dysfunction in type 2 diabetes (T2D) is a common finding and represents an early sign of diabetic cardiomyopathy. However, the relationship between LV diastolic dysfunction and the incident T2D has not been previously studied.

Methods: A total of 1817 non-diabetic participants (mean age, 54 years; 48\% men) from the Korean Genome and Epidemiology Study who were free of cardiovascular disease were studied. LV structure and function were assessed by conventional echocardiography and tissue Doppler imaging. Subclinical LV diastolic dysfunction was defined using age-specific cutoff limits for early diastolic (Em) velocity, mitral E/Em ratio, and left atrial volume index.

Results: During the 6-year follow-up period, 273 participants (15\%) developed T2D. Participants with incident T2D had greater LV mass index $\left(86.7 \pm 16.4 \mathrm{vs} .91 .2 \pm 17.0 \mathrm{~g} / \mathrm{m}^{2}\right)$, worse diastolic function, reflected by lower Em velocity $(7.67 \pm 1.80$ vs. $7.47 \pm 1.70)$ and higher E/Em ratio $(9.19 \pm 2.55$ vs. $10.23 \pm 3.00)$, and higher prevalence of LV diastolic dysfunction (34.6 vs. 54.2\%), compared with those who did not develop T2D (all $P<0.001$ ). In a multivariate logistic regression model, lower Em velocity (odd ratio [OR], 0.867; 95\% confidence interval [CI] 0.786-0.957) and the presence of LV diastolic dysfunction (OR, 1.617; 95\% Cl 1.191-2.196) were associated with the development of T2D, after adjusting for potential confounding factors.
\end{abstract}

Conclusions: In a community-based cohort, the presence of subclinical LV diastolic dysfunction was a predictor of the progression to T2D. These data suggest that the echocardiographic assessment of LV diastolic function may be helpful in identifying non-diabetic subjects at risk of incident T2D.

Keywords: Left ventricle, Diastolic dysfunction, Tissue Doppler echocardiography, Type 2 diabetes, Cohort

\section{Background}

Recent advances in cardiovascular imaging technology have facilitated the detection of underlying subclinical target organ damage, which is useful for both the prediction of future cardiovascular disease (CVD) and risk

\footnotetext{
*Correspondence: cardioguy@korea.ac.kr

†Juri Park and Jin-Seok Kim have contributed equally to this paper and

should be considered joint first authors

${ }^{11}$ Division of Cardiology, Department of Internal Medicine, Korea University Ansan Hospital, 123, Jeokgeum-ro, Danwon-gu, Ansan, Gyeonggi-do 15355, South Korea

Full list of author information is available at the end of the article
}

stratification even in asymptomatic individuals with type 2 diabetes (T2D) [1, 2]. From a large body of experimental and clinical studies, it is already recognized that T2D is associated with various types of subclinical target organ damage resulting in an elevated risk of CVD events [3-5]. Moreover, there is growing evidence that a prediabetic status, such as impaired fasting glucose and impaired glucose tolerance, is also related to subclinical target organ damage when compared to a group with normal glucose metabolism (NGM) [6, 7].

Among the various forms of preclinical target organ damage observed in T2D, impaired left ventricular (LV) 
diastolic function, assessed using the combination of conventional and tissue Doppler imaging (TDI) echocardiography, is known to be an early sign of diabetic cardiomyopathy, even in the presence of normal LV systolic function [8]. Indeed, according to the typical sequence of the occurrence of target organ damage and T2D as indicated by the traditional CV continuum, T2D should antedate the development of subclinical target organ damage, such as LV diastolic dysfunction. However, considering recent studies and the available data on the association between prediabetes and an increased risk of $\mathrm{CV}$ events $[9,10]$, the presence of preclinical target organ damage in prediabetic patients seems to play an important role similar to that of T2D. In addition, in a recent study, the presence of subclinical target organ damage, including LV hypertrophy and carotid atherosclerosis, was shown to be a significant predictor of the development of new onset diabetes in hypertensive patients, independent of traditional CV risk factors [2]. However, it is still unclear whether the presence of asymptomatic target organ damage could help to identify sub-populations of nondiabetic individuals who are at increased risk of incident T2D. Accordingly, the present analysis was designed to evaluate the prospective relation between the presence of baseline LV diastolic dysfunction and the development of $\mathrm{T} 2 \mathrm{D}$ in the general population.

\section{Methods}

\section{Study population}

Study subjects were recruited from an ongoing population-based Ansan cohort embedded in the Korean Genome Epidemiology Study, as previously described in detail [11]. The baseline cohort population (cycle 1) comprised 5020 members and has been followed biennially. This 6-year follow-up study (cycles 4-7) included the 3255 individuals who participated in the fourth cycle of the 2-year follow-up study (cycle 4) from March 12, 2007 to April 15, 2009 since the first echocardiographic study was performed at examination cycle 4 . Those with known T2D and unavailable data on baseline glucose tolerance results were excluded at baseline $(\mathrm{n}=721)$. Among 2,534 participants, we excluded if they had incomplete echocardiography data $(\mathrm{n}=302)$; known CVD including previous history of myocardial infarction, coronary revascularization, angina, congestive heart failure, stroke, congenital heart disease, cardiomyopathy, significant valvular heart disease, arrhythmia, and an ejection fraction $<50 \%(\mathrm{n}=26)$; or a serum creatinine level $\geq 2.0 \mathrm{mg} /$ $\mathrm{dL}(\mathrm{n}=3)$. Additionally, non-diabetic participants who did not take part in the last visit (cycle 7) were also excluded $(\mathrm{n}=518)$, leaving a total of 1817 subjects for the analysis.
The protocol of the study was approved by the Human Subjects Review Committee at the Korea University Ansan Hospital and all participants gave written informed consent.

\section{Measurements and definitions}

Clinical information on demographics, CV risk factors, and medical history was obtained using intervieweradministered questionnaires. Family history of diabetes was defined as having a first-degree relative with diabetes. Height $(\mathrm{cm})$ and body weight $(\mathrm{kg})$ were measured and body mass index (BMI, $\mathrm{kg} / \mathrm{m}^{2}$ ) was calculated. Subjects with $\mathrm{BMI} \geq 23 \mathrm{~kg} / \mathrm{m}^{2}$ were regarded as overweight according to Asian criteria [12]. Blood pressure was measured according to a standardized protocol using a mercury sphygmomanometer. According to the current guidelines, hypertension was defined as a systolic blood pressure $\geq 140 \mathrm{mmHg}$ and/or diastolic blood pressure $\geq 90 \mathrm{mmHg}$ and/or use of antihypertensive medication. After an at least an 8- to 14-h overnight fast, blood samples were collected for the measurement of serum total cholesterol, high-density lipoprotein (HDL) cholesterol, triglycerides (TG), fasting plasma glucose, fasting insulin, $\mathrm{HbA1c}$, serum creatinine, and highsensitivity C-reactive protein (hsCRP). The homeostasis model assessment insulin resistance index (HOMA-IR) was calculated as fasting serum insulin $(\mu \mathrm{U} / \mathrm{mL}) \times$ fasting plasma glucose $(\mathrm{mg} / \mathrm{dL}) / 405$. In order to assess glucose tolerance status, all participants without known T2D underwent a 2-h 75-g oral glucose tolerance test at inclusion (cycle 4) and then biennially during a 6-year period. The definitions of NGM, prediabetes, and T2D were made according to 2016 ADA criteria [1]. NGM was defined as the presence of the following: a fasting plasma glucose $<100 \mathrm{mg} / \mathrm{dL}$, a 2 -h plasma glucose $<140 \mathrm{mg} /$ $\mathrm{dL}$, and $\mathrm{HbA} 1 \mathrm{c}<5.7 \%$. Prediabetes was defined as having impaired fasting glucose (fasting plasma glucose of 100-125 mg/dL) and/or impaired glucose tolerance (glucose of $140-199 \mathrm{mg} / \mathrm{dL}$ on a $2-\mathrm{h}$ 75-g oral glucose tolerance test) and/or HbA1c of 5.7-6.4\%. Incident T2D was defined as a fasting plasma glucose $\geq 126 \mathrm{mg} / \mathrm{dL}$, a 2 -h postprandial plasma glucose $\geq 200 \mathrm{mg} / \mathrm{dL}, \mathrm{HbA1c} \geq 6.5 \%$ or self-reported current use of anti-diabetic drugs or insulin at any follow-up examination cycle.

\section{Echocardiography}

All echocardiographic examinations were performed using the Vivid 7 system (GE Vingmed, Horton, Norway) with a $4-\mathrm{MHz}$ transducer according to the current recommendations [13]. Cardiac chamber diameters and wall thickness were measured by M-mode echocardiography. The area-length method and Devereux formula were used to calculate the left atrial (LA) volume and LV 
mass, respectively. Both LA volume and LV mass were indexed to body surface area and expressed as LA volume index and LV mass index. LV ejection fraction measurement was obtained using the modified biplane Simpson's method. Transmitral peak $\mathrm{E}$ and peak A diastolic velocities and early mitral flow deceleration time (DT) were recorded at the tips of the mitral valve leaflets in an apical 4-chamber view. Tissue Doppler imaging of both peak systolic $(\mathrm{Sm})$ and peak early diastolic $(\mathrm{Em})$ velocities was measured at the septal side of the mitral annulus. Subsequently, the mitral E/Em ratio was calculated as an index of LV diastolic filling pressure. Echocardiographic LV hypertrophy was defined as an LV mass index $>95 \mathrm{~g} / \mathrm{m}^{2}$ in women and $>115 \mathrm{~g} / \mathrm{m}^{2}$ in men. LV diastolic dysfunction was defined based on a reduced septal TDI Em velocity, septal E/Em ratio $>15$, or LA volume index $\geq 34 \mathrm{~mL} / \mathrm{m}^{2}$ [14]. To define a reduced septal TDI Em velocity, an agespecific abnormal value for septal TDI Em velocity was calculated as a value greater than one standard deviation below the mean reference value adjusted for age, since the TDI Em velocity is highly dependent on age $[4,15]$.

\section{Statistical analysis}

Baseline demographic and echocardiographic data were presented as means \pm standard deviations for continuous variables or as percentages for categorical variables. Differences between groups stratified by incident T2D were assessed using the Student's $t$ test for continuous variables or the $\chi^{2}$ test for categorical variables. Additionally, univariate logistic regression analyses were used to estimate the odds ratios of known cardiometabolic risk factors and echocardiographic parameters for the development of T2D. Finally, a multivariate logistic regression model tested the predictive value of each of the echocardiographic variables and the presence of baseline LV diastolic dysfunction for progression to T2D using age, sex, BMI $\geq 23 \mathrm{~kg} /$ $\mathrm{m}^{2}$, baseline glucose metabolism (NGM vs. prediabetes), hypertension, statin therapy, family history of diabetes, smoking status, alcohol intake, HOMA-IR, total cholesterol, TG/HDL ratio, and hsCRP as potential confounders. Covariates for the multivariate model were selected on the basis of univariate analyses and known risk factors for diabetes proposed by the latest diabetes guidelines [1]. To examine the effect of baseline glucose status, we performed additional multivariate logistic regression analyses after stratifying participants into two groups: "NGM" and "prediabetes". For the multiple hypotheses testing, we corrected $\mathrm{P}$ values using the Bonferroni method based on the raw $P$ values of logistic regression.

A P value $<0.05$ was considered significant for all analyses. SAS version 9.3 (SAS institute, Cary, NC, USA) was used for all analyses.

\section{Results}

Baseline demographic, metabolic, and echocardiographic characteristics

Table 1 shows the baseline characteristics of the study subjects after stratification by incident T2D. Among the 1817 subjects without known CVD, 788 (43.4\%) participants had NGM and 1029 (56.6\%) had prediabetes at baseline according to ADA recommendations. Over the 6-year of follow-up period, 273 (129 males and 144 females) new cases of T2D occurred and 244 participants with incident T2D were prediabetic at inclusion. Overall, the subjects who developed incident T2D subjects displayed significant disturbances in various metabolic profiles at baseline, compared to participants without incident T2D. However, groups did not differ with regard to gender, heart rate, alcohol consumption, total cholesterol, and serum creatinine.

Table 2 shows that the participants developing T2D had higher baseline relative wall thickness, LV mass index, mitral inflow A velocity, DT, and E/Em ratio, with lower baseline mitral inflow $\mathrm{E}$ velocity, mitral inflow $\mathrm{E} / \mathrm{A}$ ratio, and TDI Sm and Em velocities compared to those without incident T2D (all $P<0.05$ ). The prevalence of LV hypertrophy and LV diastolic dysfunction was also higher in participants developing T2D (all $P<0.05$ ). On the other hand, no significant differences in terms of LA volume index and LV ejection fraction were shown.

\section{Independent predictors of incident T2D}

After 6 years, the development of T2D was associated with baseline age, excessive body weight, the presence of prediabetes and hypertension, statin therapy, current smoking, HbA1c, HOMA-IR, low HDL-cholesterol level, high TG level, hsCRP, and family history of diabetes in univariate analyses (all $P<0.05$ ).

Table 3 shows that various echocardiographic LV structural and functional parameters except for LA volume index and the presence of LV hypertrophy and LV diastolic dysfunction were independent predictors for the development of T2D in univariate analyses. When each echocardiographic parameter was separately forced into a multivariate logistic regression model including age, sex, BMI $\geq 23 \mathrm{~kg} / \mathrm{m}^{2}$, baseline glucose metabolism (NGM vs. prediabetes), hypertension, statin therapy, family history of diabetes, smoking status, alcohol intake, HOMAIR, TG/HDL ratio, and hsCRP, only TDI Em velocity was inversely and independently associated with incident T2D. Similarly, the risk of 6-year incidence of T2D increased by $62 \%$ in the presence of baseline LV diastolic dysfunction, regardless of baseline glucose metabolism status (Table 3). None of the echocardiographic measurements of LV systolic function showed significant predictive effect. 
Table 1 Baseline demographic and laboratory characteristics of the study participants developing or not developing type 2 diabetes at the follow-up

\begin{tabular}{|c|c|c|c|c|}
\hline Variable & All participants $(n=1817)$ & $\begin{array}{l}\text { Not developing type } 2 \text { diabetes } \\
(\mathrm{n}=1544)\end{array}$ & $\begin{array}{l}\text { Developing type } 2 \text { diabetes } \\
(\mathrm{n}=273)\end{array}$ & $P$ value \\
\hline Age (years) & $53.5 \pm 6.7$ & $53.1 \pm 6.4$ & $55.7 \pm 7.5$ & $<0.001$ \\
\hline Male (\%) & 47.9 & 48.1 & 47.3 & 0.844 \\
\hline $\mathrm{BMI}\left(\mathrm{kg} / \mathrm{m}^{2}\right)$ & $24.5 \pm 2.7$ & $24.3 \pm 2.6$ & $25.4 \pm 2.8$ & $<0.001$ \\
\hline Systolic BP (mmHg) & $110.3 \pm 13.5$ & $109.4 \pm 13.3$ & $115.1 \pm 13.6$ & $<0.001$ \\
\hline Diastolic BP (mmHg) & $74.6 \pm 9.5$ & $74.3 \pm 9.6$ & $76.1 \pm 9.1$ & 0.002 \\
\hline Heart rate (bpm) & $65.0 \pm 6.9$ & $64.9 \pm 6.9$ & $65.4 \pm 6.9$ & 0.318 \\
\hline Hypertension (\%) & 22.1 & 19.7 & 35.9 & $<0.001$ \\
\hline Antihypertensive therapy (\%) & 16.8 & 14.5 & 29.7 & $<0.001$ \\
\hline Fasting glucose (mg/dL) & $90.9 \pm 8.4$ & $89.9 \pm 7.8$ & $96.3 \pm 9.7$ & $<0.001$ \\
\hline 2-h glucose (mg/dL) & $134.3 \pm 30.6$ & $129.8 \pm 28.4$ & $160.0 \pm 29.7$ & $<0.001$ \\
\hline Fasting insulin ( $\mu \mathrm{lU} / \mathrm{mL})$ & $8.70 \pm 4.03$ & $8.52 \pm 3.99$ & $9.71 \pm 4.12$ & $<0.001$ \\
\hline $\mathrm{HbA1c}(\%)$ & $5.43 \pm 0.35$ & $5.39 \pm 0.33$ & $5.65 \pm 0.38$ & $<0.001$ \\
\hline HOMA-IR & $1.97 \pm 0.98$ & $1.91 \pm 0.95$ & $2.33 \pm 1.06$ & $<0.001$ \\
\hline Family history of diabetes (\%) & 17.5 & 16.6 & 22.7 & 0.016 \\
\hline Glucose metabolism (\%) & & & & $<0.001$ \\
\hline NGM & 43.4 & 49.2 & 10.6 & \\
\hline Prediabetes & 56.6 & 50.8 & 89.4 & \\
\hline Current smoker (\%) & 13.5 & 14.3 & 9.2 & 0.021 \\
\hline Current alcohol drinker (\%) & 50.0 & 50.1 & 49.5 & 0.896 \\
\hline Total cholesterol (mg/dL) & $202.5 \pm 34.2$ & $202.1 \pm 34.5$ & $204.8 \pm 32.9$ & 0.217 \\
\hline HDL-cholesterol (mg/dL) & $45.5 \pm 10.6$ & $45.9 \pm 10.6$ & $43.5 \pm 10.5$ & 0.001 \\
\hline Triglycerides (mg/dL) & $134.6 \pm 83.0$ & $129.6 \pm 79.5$ & $162.3 \pm 96.1$ & $<0.001$ \\
\hline Statin therapy (\%) & 2.5 & 1.4 & 3.4 & 0.007 \\
\hline hsCRP (mg/L) & $1.39 \pm 4.17$ & $1.28 \pm 3.93$ & $2.03 \pm 5.31$ & 0.006 \\
\hline Creatinine (mg/dL) & $0.95 \pm 0.15$ & $0.95 \pm 0.14$ & $0.96 \pm 0.16$ & 0.282 \\
\hline
\end{tabular}

$B M I$ body mass index, $B P$ blood pressure, $H D L$ high-density lipoprotein, HOMA-IR homeostasis model assessment-insulin resistance, $h s C R P$ high sensitivity C-reactive protein, NGM normal glucose metabolism

The multivariate logistic regression analyses, adjusting for age, sex, BMI $\geq 23 \mathrm{~kg} / \mathrm{m}^{2}$, fasting plasma glucose, $2-\mathrm{h}$ plasma glucose, mean blood pressure, family history of diabetes, smoking status, alcohol intake, HOMA-IR, total cholesterol, TG/HDL ratio, and hsCRP, were also performed in a specific subpopulation stratified according to the baseline glucose metabolism (NGN vs. prediabetes). Prediabetic individuals were older, more frequent alcohol drinker, had higher baseline BMI, systolic and diastolic blood pressures, heart rate, total cholesterol, triglycerides, hsCRP, lower HDL-cholesterol, and more frequent family history of diabetes (all $P<0.05$ ) than participants with NGM. In the prediabetic population, incident T2D was independently predicted by the presence of $\mathrm{LV}$ diastolic dysfunction, but any of the echocardiographic parameters, even with the presence of LV diastolic dysfunction, could not predict the development of T2D in subjects with NGM (Table 4).

In a subgroup analysis, we conducted post hoc power analyses using GPower software with power at 0.80 and alpha $=0.05$ (two-tailed) to estimate the sample sizes for LV diastolic parameters and the presence of LV diastolic function. This showed us that the sample sizes in NGM group would have to increase up to 14,132 and 311,264 for TDI Em velocity and LV diastolic dysfunction, respectively, to reach statistical significance at the 0.05 level. Therefore, it is unlikely that our negative results in subjects with NGM can be attributed to a limited sample size.

\section{Discussion}

We found that the presence of LV diastolic dysfunction, one of the various types of target organ damage induced by overt T2D, was a significant predictor of incident T2D, independent of various cardiometabolic profiles. In addition, $\mathrm{LV}$ diastolic markers such as mitral inflow $\mathrm{E} / \mathrm{A}$ ratio, TDI Em velocity, and E/Em ratio as continuous variables were also associated with an increased incidence of T2D. This finding was confirmed in a subgroup of prediabetes, whereas neither LV diastolic parameters nor 
Table 2 Baseline echocardioraphic parameters of the study participants developing or not developing type 2 diabetes at the follow-up

\begin{tabular}{|c|c|c|c|c|}
\hline Variable & Total $(n=1817)$ & $\begin{array}{l}\text { Not developing type } 2 \text { diabe- } \\
\text { tes }(n=1544)\end{array}$ & $\begin{array}{l}\text { Developing type } 2 \text { diabetes } \\
(n=273)\end{array}$ & $P$ value \\
\hline $\mathrm{LA}$ volume index $\left(\mathrm{mL} / \mathrm{m}^{2}\right)$ & $26.2 \pm 6.3$ & $26.1 \pm 6.3$ & $26.7 \pm 6.4$ & 0.181 \\
\hline Relative wall thickness & $0.37 \pm 0.06$ & $0.36 \pm 0.06$ & $0.39 \pm 0.07$ & $<0.001$ \\
\hline LV mass (g) & $150 \pm 37$ & $149 \pm 37$ & $158 \pm 38$ & $<0.001$ \\
\hline LV mass index $\left(\mathrm{g} / \mathrm{m}^{2}\right)$ & $87.3 \pm 16.6$ & $86.7 \pm 16.4$ & $91.2 \pm 17.0$ & $<0.001$ \\
\hline LV hypertrophy (\%) & 13.9 & 13.1 & 18.7 & 0.017 \\
\hline LV ejection fraction (\%) & $65.0 \pm 4.5$ & $65.1 \pm 4.5$ & $64.7 \pm 4.5$ & 0.235 \\
\hline \multicolumn{5}{|l|}{ Mitral inflow velocity } \\
\hline $\mathrm{E}, \mathrm{cm} / \mathrm{s}$ & $0.68 \pm 0.15$ & $0.68 \pm 0.15$ & $0.66 \pm 0.15$ & 0.039 \\
\hline $\mathrm{A}, \mathrm{cm} / \mathrm{s}$ & $0.63 \pm 0.17$ & $0.62 \pm 0.17$ & $0.70 \pm 0.18$ & $<0.001$ \\
\hline E/A ratio & $1.15 \pm 0.36$ & $1.17 \pm 0.37$ & $0.99 \pm 0.30$ & $<0.001$ \\
\hline DT, ms & $195 \pm 47$ & $195 \pm 47$ & $200 \pm 47$ & 0.091 \\
\hline \multicolumn{5}{|l|}{ Tissue Doppler imaging (TDI) } \\
\hline TDI Sm velocity $(\mathrm{cm} / \mathrm{s})$ & $7.68 \pm 1.29$ & $7.70 \pm 1.29$ & $7.47 \pm 1.27$ & 0.018 \\
\hline TDI Em velocity $(\mathrm{cm} / \mathrm{s})$ & $7.57 \pm 1.83$ & $7.67 \pm 1.80$ & $7.47 \pm 1.70$ & $<0.001$ \\
\hline E/Em ratio & $9.31 \pm 2.62$ & $9.19 \pm 2.55$ & $10.23 \pm 3.00$ & $<0.001$ \\
\hline LV diastolic dysfunction (\%) & 37.5 & 34.6 & 54.2 & $<0.001$ \\
\hline
\end{tabular}

$D T$ deceleration time, $L A$ left atrium, $L V$ left ventricle

Table 3 Baseline echocardiographic parameters associated with incident type 2 diabetes

\begin{tabular}{|c|c|c|c|c|c|}
\hline \multirow[t]{2}{*}{ Variables } & \multicolumn{2}{|l|}{ Univariate } & \multicolumn{3}{|l|}{ Multivariate $^{\mathrm{a}}$} \\
\hline & OR $(95 \% \mathrm{CI})$ & $P$ value & OR $(95 \% \mathrm{Cl})$ & $P$ value & $P$ value ${ }^{b}$ \\
\hline LA volume index $\left(\mathrm{mL} / \mathrm{m}^{2}\right)$ & $1.013(0.993-1.034)$ & 0.189 & $1.017(0.995-1.040)$ & 0.133 & 0.933 \\
\hline LV mass index $\left(\mathrm{g} / \mathrm{m}^{2}\right)$ & $1.016(1.008-1.024)$ & $<0.001$ & $1.009(1.000-1.018)$ & 0.040 & 0.283 \\
\hline LV hypertrophy (yes vs. no) & $1.526(1.088-2.141)$ & 0.014 & $1.198(0.806-1.780)$ & 0.371 & 1.000 \\
\hline TDI Sm velocity (cm/s) & $0.856(0.772-0.949)$ & 0.003 & $0.914(0.816-1.024)$ & 0.119 & 0.836 \\
\hline TDI Em velocity $(\mathrm{cm} / \mathrm{s})$ & $0.742(0.685-0.804)$ & $<0.001$ & $0.867(0.786-0.957)$ & 0.004 & 0.031 \\
\hline E/Em ratio & $1.147(1.094-1.201)$ & $<0.001$ & $1.076(1.017-1.137)$ & 0.010 & 0.071 \\
\hline LV diastolic dysfunction (yes vs. no) & $2.239(1.726-2.905)$ & $<0.001$ & $1.617(1.191-2.196)$ & 0.002 & 0.014 \\
\hline
\end{tabular}

$B M I$ body mass index, $C l$ confidence interval, $H D L$ high-density lipoprotein, $H O M A-I R$ homeostasis model assessment-insulin resistance, $h s C R P$ high sensitivity C-reactive protein, $L A$ left atrium, $L V$ left ventricle, NGM normal glucose metabolism, OR odds ratio, TDI tissue Doppler imaging, TG triglycerides

a Model was adjusted for age, sex, BMI $\geq 23 \mathrm{~kg} / \mathrm{m}^{2}$, baseline glucose metabolism (NGM vs. prediabetes), hypertension, statin therapy, family history of diabetes, smoking status, alcohol intake, HOMA-IR, total cholesterol, TG/HDL ratio, and hsCRP. Each echocardiographic variable was tested separately in a multivariate model

b Corrected $\mathrm{P}$ values using Bonferroni method for multiple comparisons

the existence of LV diastolic dysfunction were associated with the risk of incident T2D in participants with NGM.

\section{Association of CV risk factors with target organ damage} According to the $\mathrm{CV}$ continuum theory, a clear temporal relationship exists whereby various $\mathrm{CV}$ risk factors, such as hypertension and T2D, generally precede the development of target organ damage. However, recent literatures have reported that increased LV mass and arterial stiffness are predictors of incident hypertension in both normotensive and prehypertensive individuals [16, 17]. Moreover, our previous findings demonstrated that the clustering of target organ damage types, including LV hypertrophy, LV diastolic dysfunction, carotid atherosclerosis, and arterial stiffness, substantially increases the risk of developing hypertension in the non-hypertensive population, irrespective of baseline BP category and obesity status [18]. Similar to previous reports regarding the temporal correlation between incident hypertension and preclinical types of target organ damage, Izzo et al. [2] reported that the presence of target organ damage, such as LV hypertrophy and carotid atherosclerosis, is a significant predictor of new-onset T2D in a population of treated hypertensive patients. Thus, these findings, which 
Table 4 Echocardiographic predictors of incident type 2 diabetes in a subgroup stratified according to baseline glucose metabolism (NGM vs. prediabetes), adjusting for age, sex, BMI $\geq 23 \mathrm{~kg} / \mathrm{m}^{2}$, fasting plasma glucose, 2-h plasma glucose, hypertension, statin therapy, family history of diabetes, smoking status, alcohol intake, HOMA-IR, total cholesterol, TG/ HDL ratio, and hsCRP: multivariate logistic regression analyses

\begin{tabular}{|c|c|c|c|c|c|c|}
\hline \multirow[t]{2}{*}{ Variables } & \multicolumn{3}{|l|}{$\operatorname{NGM}(n=788)$} & \multicolumn{3}{|c|}{ Prediabetes $(n=1029)$} \\
\hline & OR $(95 \% \mathrm{Cl})$ & $P$ value & $P$ value ${ }^{a}$ & OR $(95 \% \mathrm{Cl})$ & $P$ value & $P$ value ${ }^{a}$ \\
\hline LA volume index $\left(\mathrm{mL} / \mathrm{m}^{2}\right)$ & $1.037(0.982-1.095)$ & 0.190 & 1.000 & $1.021(0.993-1.048)$ & 0.140 & 1.000 \\
\hline LV mass index $\left(\mathrm{g} / \mathrm{m}^{2}\right)$ & $0.999(0.973-1.026)$ & 0.948 & 1.000 & $1.014(1.004-1.025)$ & 0.009 & 0.126 \\
\hline LV hypertrophy (yes vs. no) & $0.848(0.268-2.683)$ & 0.779 & 1.000 & $1.315(0.833-2.074)$ & 0.240 & 1.000 \\
\hline TDI Sm velocity $(\mathrm{cm} / \mathrm{s})$ & $0.892(0.633-1.257)$ & 0.513 & 1.000 & $0.872(0.764-0.995)$ & 0.041 & 0.574 \\
\hline TDI Em velocity (cm/s) & $0.958(0.725-1.267)$ & 0.765 & 1.000 & $0.864(0.770-0.968)$ & 0.012 & 0.168 \\
\hline E/Em ratio & $1.078(0.900-1.292)$ & 0.416 & 1.000 & $1.064(1.000-1.134)$ & 0.051 & 0.714 \\
\hline LV diastolic dysfunction (yes vs. no) & $1.000(0.389-2.575)$ & 0.999 & 1.000 & $1.906(1.335-2.721)$ & $<0.001$ & 0.005 \\
\hline
\end{tabular}

$B M I$ body mass index, $C l$ confidence interval, $H D L$ high-density lipoprotein, $H O M A-I R$ homeostasis model assessment-insulin resistance, $h s C R P$ high sensitivity C-reactive protein, $L V$ left ventricle, NGM normal glucose metabolism, OR odds ratio, TDI tissue Doppler imaging, TG triglycerides

a Corrected $\mathrm{P}$ values using Bonferroni method for multiple comparisons

are different from the traditional concept of CV continuum, suggest that the presence of several types of asymptomatic target organ damage may be helpful in predicting incident T2D and hypertension.

\section{Association of glucose metabolism with cardiac function}

To our knowledge, no epidemiological study has specifically linked preclinical LV diastolic dysfunction to incident T2D. Instead, previous cross-sectional studies have shown that subtle abnormalities of LV systolic and/ or diastolic function, which are key components of the progression to diabetic cardiomyopathy, are frequently detected in T2D [4, 19-23]. Although the exact causes leading to the LV changes in patients with T2D remain still unclear, the reduction of coronary flow reserve, metabolic abnormality, autonomic dysfunction, and myocardial fibrosis have been reported as possible mechanisms of subclinical myocardial damage [24]. Besides these data, subclinical LA structural and functional changes are also known to be common findings in patients with T2D [25-27]. Interestingly, Wang et al. reported that LA energy loss and deformation mechanics are already impaired even in T2D patients with normal LA size [27]. Overall, the duration of diabetes, diabetic complications, hypertriglycemia, obesity status, blood pressure, and glycemic control in asymptomatic patients with T2D were closely related to LA remodeling and LV diastolic dysfunction. However, according to recent observations, the high prevalence of subclinical LV systolic and/or diastolic dysfunction has been noted in prediabetic subjects compared to those with normal glucose metabolism, although prediabetes have intermediate values for various indices of LV systolic and diastolic function between normal and diabetic states $[6,28]$. In addition, an association of prediabetes with other types of target organ damage, such as carotid atherosclerosis and arterial stiffness, has been reported, independent of other potential metabolic risk factors [7, 29]. As a result, although the clinical significance of early subclinical changes in the $\mathrm{CV}$ system observed in the prediabetic population has been in question in previous cross-sectional studies, the prognostic impact of LV diastolic dysfunction in prediabetes from our findings supports the hypothesis that preclinical target organ damage may be predictive of $\mathrm{T} 2 \mathrm{D}$ development.

Although the exact mechanism linking the impairment of LV diastolic function to incident T2D in prediabetic individuals could not be determined in the current analysis, it can be hypothesized that the disturbance of myocardial insulin signaling plays an important role in its pathogenesis [30]. Similar to the relationship between insulin resistance and its associated CV complications in overt T2D, recent studies have indicated that higher levels of insulin resistance were related to the impairment of cardiac and vascular function compared to those with lower insulin resistance in a non-diabetic population $[31,32]$. Therefore, considering that insulin resistance is a characteristic feature of $\mathrm{T} 2 \mathrm{D}$, and that higher levels of HOMA index were associated with incident T2D, our suggestion that prediabetic subjects with LV diastolic dysfunction are at higher risk of developing overt T2D appears plausible.

\section{Limitations}

Our study has several limitations. Firstly, not all of the parameters for the precise evaluation of LV diastolic function were measured. Therefore, although previous studies reported a wide range of the prevalence of LV 
diastolic dysfunction ranging from 11.1 to $34.7 \%$ in the general population [33], the prevalence $(37.5 \%)$ of LV diastolic dysfunction as determined in our study seems somewhat high. Nevertheless, given that each measured value for assessing LV diastolic function was an independent predictor of incident T2D, the arbitrary definition of LV diastolic dysfunction used in our study seems acceptable. Another limitation is that since our cohort members were all Korean, so to apply our findings to other ethnicities may not be valid. Thus, additional research is required.

\section{Conclusions}

Left ventricular diastolic parameters and the presence of LV diastolic dysfunction were independent predictors of 6-year incident T2D in a population-based sample without overt CVD. These findings may have potential clinical implications for primary $\mathrm{CV}$ prevention because early identification of LV diastolic dysfunction could offer substantial opportunities to delay the development of T2D through more aggressive and preventive strategies, especially in the prediabetic population at high risk for developing T2D. Although the current guidelines do not recommend the routine use of screening tests to search for asymptomatic target organ damage in non-diabetic individuals, our study suggest that cardiac ultrasound may be a useful screening tool in a clinical practice. Future trials are needed to determine whether earlier and more aggressive intervention could prevent or delay the development of T2D in these individuals.

\section{Abbreviations \\ BMI: body mass index; CVD: cardiovascular disease; DT: deceleration time; HDL: high-density lipoprotein; HOMA-IR: homeostasis model assessment insulin resistance index; hsCRP: high-sensitivity C-reactive protein; LA: left atrium; LV: left ventricle; NGM: normal glucose metabolism; TDI: tissue Doppler imaging; TG: triglycerides; T2D: type 2 diabetes.}

\section{Authors' contributions \\ JP and JSK are co-primary authors of the manuscript and wrote the manu- script. SK, SYL, and HEL collected the data and edited the manuscript. GYC, KCS, JYK, and JBL designed the echocardiography study and assisted with image and data analysis. IB, KKK, and SKL reviewed the manuscript critically for important intellectual content. CS assisted with study design and funding application. SHK is the guarantor of this work and, as such, had full access to all the data in the study and takes responsibility for the integrity of the data and the accuracy of the data analysis. All authors read and approved the final manuscript.}

\footnotetext{
Author details

1 Department of Endocrinology, Hallym University Kangdong Sacred Heart Hospital, Seoul, South Korea. ${ }^{2}$ Department of Cardiology, Korea University Ansan Hospital, Ansan, South Korea. ${ }^{3}$ Cardiovascular Center, Korea University Guro Hospital, Seoul, South Korea. ${ }^{4}$ Department of Cardiology, Seoul National University Bundang Hospital, Seongnam, South Korea. ${ }^{5}$ Department of Cardiology, Kangbuk Samsung Hospital, Seoul, South Korea. ${ }^{6}$ Department of Cardiology, Wonju College of Medicine, Yonsei University, Wonju, South Korea.

${ }^{7}$ Department of Foods and Nutrition, Kookmin University, Seoul, South Korea.

${ }^{8}$ Department of Cardiology, Gachon University Gil Medical Center, Incheon,
}

South Korea. ${ }^{9}$ Department of Clinical Epidemiology and Biostatistics, Asan Medical Center, Seoul, South Korea. ${ }^{10}$ Institute of Human Genomic Study, Korea University Ansan Hospital, Ansan, South Korea. ${ }^{11}$ Division of Cardiology, Department of Internal Medicine, Korea University Ansan Hospital, 123, Jeokgeum-ro, Danwon-gu, Ansan, Gyeonggi-do 15355, South Korea.

\section{Acknowledgements}

The authors thank the investigators, the staff, and the participants of the KoGES for their contributions.

\section{Competing interests}

The authors declare that they have no competing interests.

\section{Availability of data and materials}

The datasets used and analyzed during the current study are available from the corresponding author on reasonable request.

\section{Ethics approval and consent to participate}

The protocol of the study was approved by the Human Subjects Review Committee at the Korea University Ansan Hospital and all participants gave written informed consent

\section{Funding}

This study was supported by Grants (2007-E71001-00, 2008-E71001-00, 2009E71002-00, 2010-E71001-00, 2011-E71004-00, and 2012-E71005-00) from the Korean Centers for Disease Control and Prevention, and a Grant (Q1522781) from the Korea University Medical Center.

Received: 28 October 2016 Accepted: 6 March 2017

Published online: 14 March 2017

\section{References}

1. Standards of Medical Care in Diabetes-2016: summary of revisions. Diabetes Care. 2016;39 Suppl 1: S4-5.

2. Izzo R, de Simone G, Trimarco V, Gerdts E, Giudice R, Vaccaro O, De Luca N, Trimarco B. Hypertensive target organ damage predicts incident diabetes mellitus. Eur Heart J. 2013;34:3419-26.

3. Yoshida M, Mita T, Yamamoto R, Shimizu T, Ikeda F, Ohmura C, Kanazawa A, Hirose T, Kawamori R, Watada H. Combination of the Framingham risk score and carotid intima-media thickness improves the prediction of cardiovascular events in patients with type 2 diabetes. Diabetes Care. 2012;35:178-80.

4. Fang ZY, Schull-Meade R, Downey M, Prins J, Marwick TH. Determinants of subclinical diabetic heart disease. Diabetologia. 2005:48:394-402.

5. Anand DV, Lim E, Hopkins D, Corder R, Shaw LJ, Sharp P, Lipkin D, Lahiri A. Risk stratification in uncomplicated type 2 diabetes: prospective evaluation of the combined use of coronary artery calcium imaging and selective myocardial perfusion scintigraphy. Eur Heart J. 2006;27:713-21.

6. Ceyhan K, Kadi H, Koç F, Celik A, Oztürk A, Onalan O. Longitudinal left ventricular function in normotensive prediabetics: a tissue Doppler and strain/strain rate echocardiography study. J Am Soc Echocardiogr. 2012;25:349-56.

7. Loehr LR, Meyer ML, Poon AK, Selvin E, Palta P, Tanaka H, Pankow JS, Wright JD, Griswold ME, Wagenknecht LE, et al. Prediabetes and diabetes are associated with arterial stiffness in older adults: the ARIC study. Am J Hypertens. 2016;29:1038-45.

8. Jia G, DeMarco VG, Sowers JRA. Insulin resistance and hyperinsulinaemia in diabetic cardiomyopathy. Nat Rev Endocrinol. 2016;12:144-53.

9. Selvin E, Steffes MW, Zhu H, Matsushita K, Wagenknecht L, Pankow J, Coresh J, Brancati FL. Glycated hemoglobin, diabetes, and cardiovascular risk in nondiabetic adults. N Engl J Med. 2010;362:800-11.

10. Meigs JB, Nathan DM, D'Agostino RB Sr, Wilson PW, Framingham Offspring Study. Fasting and postchallenge glycemia and cardiovascular disease risk: the Framingham Offspring Study. Diabetes Care. 2002;25:1845-50.

11. Baik I, Kim J, Abbott RD, Joo S, Jung K, Lee S, Shim J, In K, Kang K, Yoo S, et al. Association of snoring with chronic bronchitis. Arch Intern Med. 2008;168:167-73. 
12. Hsu WC, Araneta MR, Kanaya AM, Chiang JL, Fujimoto W. BMI cut points to identify at-risk Asian Americans for type 2 diabetes screening. Diabetes Care. 2015;38:150-8.

13. Lang RM, Badano LP, Mor-Avi V, Afilalo J, Armstrong A, Ernande L, Flachskampf FA, Foster E, Goldstein SA, Kuznetsova T, et al. Recommendations for cardiac chamber quantification by echocardiography in adults: an update from the American Society of Echocardiography and the European Association of Cardiovascular Imaging. Eur Heart J Cardiovasc Imaging. 2015;16:233-70.

14. Nagueh SF, Appleton CP, Gillebert TC, Marino PN, Oh JK, Smiseth OA, Waggoner AD, Flachskampf FA, Pellikka PA, Evangelista A. Recommendations for the evaluation of left ventricular diastolic function by echocardiography. J Am Soc Echocardiogr. 2009;22:107-33.

15. Chahal NS, Lim TK, Jain P, Chambers JC, Kooner JS, Senior R. Normative reference values for the tissue Doppler imaging parameters of left ventricular function: a population-based study. Eur J Echocardiogr. 2010;11:51-6.

16. De Marco M, de Simone G, Roman MJ, Chinali M, Lee ET, Russell M, Howard BV, Devereux RB. Cardiovascular and metabolic predictors of progression of prehypertension into hypertension: the strong heart study. Hypertension. 2009;54:974-80.

17. de Simone G, Devereux RB, Chinali M, Roman MJ, Welty TK, Lee ET, Howard BV. Left ventricular mass and incident hypertension in individuals with initial optimal blood pressure: the strong heart study. J Hypertens. 2008;26:1868-74.

18. Kim SH, Kim YH, Kim JS, Lim SY, Jung JH, Lim HE, Kim EJ, Cho GY, Baik I, Sung KC, et al. Target-organ damage and incident hypertension: the Korean genome and epidemiology study. J Hypertens. 2016;34:524-30.

19. Poulsen MK, Henriksen JE, Dahl J, Johansen A, Gerke O, Vach W, Haghfelt T, Høilund-Carlsen PF, Beck-Nielsen H, Møller JE. Left ventricular diastolic function in type 2 diabetes mellitus: prevalence and association with myocardial and vascular disease. Circ Cardiovasc Imaging. 2010;3:24-31.

20. Mochizuki Y, Tanaka H, Matsumoto K, Sano H, Toki H, Shimoura H, Ooka J, Sawa T, Motoji Y, Ryo K, et al. Clinical features of subclinical left ventricular systolic dysfunction in patients with diabetes mellitus. Cardiovasc Diabetol. 2015;14:37.

21. Enomoto $M$, Ishizu T, Seo $Y$, Yamamoto $M$, Suzuki $H$, Shimano $H$, Kawakami Y, Aonuma K. Subendocardial systolic dysfunction in asymptomatic normotensive diabetic patients. Circ J. 2015;79:1749-55.

22. Maiello M, Zito A, Cecere A, Ciccone MM, Palmiero P. Left ventricular diastolic dysfunction in normotensive postmenopausal women with type 2 diabetes mellitus. Cardiol J. 2017;24:51-6.

23. Cassidy S, Hallsworth K, Thoma C, MacGowan GA, Hollingsworth KG, Day CP, Taylor R, Jakovljevic DG, Trenell MI. Cardiac structure and function are altered in type 2 diabetes and non-alcoholic fatty liver disease and associate with glycemic control. Cardiovasc Diabetol. 2015;14:23.

24. Kawata T, Daimon M, Miyazaki S, Ichikawa R, Maruyama M, Chiang SJ, Ito C, Sato F, Watada H, Daida H. Coronary microvascular function is independently associated with left ventricular filling pressure in patients with type 2 diabetes mellitus. Cardiovasc Diabetol. 2015;14:98.

25. Mochizuki Y, Tanaka H, Matsumoto K, Sano H, Shimoura H, Ooka J, Sawa T, Ryo-Koriyama K, Hirota Y, Ogawa W, et al. Impaired mechanics of left ventriculo-atrial coupling in patients with diabetic nephropathy. Circ J. 2016:80:1957-64.

26. Zoppini G, Bonapace S, Bergamini C, Rossi A, Trombetta M, Lanzoni L, Bertolini L, Zenari L, Bonora E, Targher G. Evidence of left atrial remodeling and left ventricular diastolic dysfunction in type 2 diabetes mellitus with preserved systolic function. Nutr Metab Cardiovasc Dis. 2016;26:1026-32.

27. Wang Y, Hou D, Ma R, Ding G, Yin L, Zhang M. Early detection of left atrial energy loss and mechanics abnormalities in diabetic patients with normal left atrial size: a study combining vector flow mapping and tissue tracking echocardiography. Med Sci Monit. 2016;22:958-68.

28. Milwidsky A, Maor E, Kivity S, Berkovitch A, Zekry SB, Tenenbaum A, Fisman EZ, Erez A, Segev S, Sidi Y, et al. Impaired fasting glucose and left ventricular diastolic dysfunction in middle-age adults: a retrospective cross-sectional analysis of 2971 subjects. Cardiovasc Diabetol. 2015;14:119.

29. Mostaza JM, Lahoz C, Salinero-Fort MA, de Burgos-Lunar C, Laguna F, Estirado E, García-Iglesias F, González-Alegre T, Cornejo-Del-Río V, Sabín $C$, et al. Carotid atherosclerosis severity in relation to glycemic status: a cross-sectional population study. Atherosclerosis. 2015;242:377-82.

30. Abel ED, O'Shea KM, Ramasamy R. Insulin resistance: metabolic mechanisms and consequences in the heart. Arterioscler Thromb Vasc Biol. 2012;32:2068-76.

31. Novo G, Manno G, Russo R, Buccheri D, Dell'Oglio S, Morreale P, Evola G, Vitale G, Novo S. Impact of insulin resistance on cardiac and vascular function. Int J Cardiol. 2016;221:1095-9.

32. Kishi S, Gidding SS, Reis JP, Colangelo LA, Venkatesh BA, Armstrong AC, Isogawa A, Lewis CE, Wu C, Jacobs DR Jr, et al. Association of insulin resistance and glycemic metabolic abnormalities with LV structure and function in middle age: the CARDIA study. JACC Cardiovasc Imaging. 2017;10:105-14.

33. Kuznetsova T, Herbots L, López B, Jin Y, Richart T, Thijs L, González A, Herregods MC, Fagard $\mathrm{RH}$, Díez J, et al. Prevalence of left ventricular diastolic dysfunction in a general population. Circ Heart Fail. 2009;2:105-12.

\section{Submit your next manuscript to BioMed Central and we will help you at every step:}

- We accept pre-submission inquiries

- Our selector tool helps you to find the most relevant journal

- We provide round the clock customer support

- Convenient online submission

- Thorough peer review

- Inclusion in PubMed and all major indexing services

- Maximum visibility for your research

Submit your manuscript at www.biomedcentral.com/submit 